\title{
Corinne Saminadayar-Perrin, Les Discours du journal, Rhétorique et médias au XIX ${ }^{\mathrm{e}}$ siècle (1836-1885)
}

\section{Philippe Andrès}

\section{(2) OpenEdition}

\section{Journals}

\section{Édition électronique}

URL : http://journals.openedition.org/studifrancesi/8282

DOI : $10.4000 /$ studifrancesi.8282

ISSN : 2421-5856

\section{Éditeur}

Rosenberg \& Sellier

\section{Édition imprimée}

Date de publication : 1 mai 2009

Pagination : 182

ISSN : 0039-2944

\section{Référence électronique}

Philippe Andrès, "Corinne Saminadayar-Perrin, Les Discours du journal, Rhétorique et médias au xix siècle (1836-1885) », Studi Francesi [En ligne], 157 (LIII | I) | 2009, mis en ligne le 30 novembre 2015, consulté le 12 janvier 2021. URL : http://journals.openedition.org/studifrancesi/8282 ; DOI : https:// doi.org/10.4000/studifrancesi.8282

Ce document a été généré automatiquement le 12 janvier 2021.

\section{(c) $(1) \&$}

Studi Francesi è distribuita con Licenza Creative Commons Attribuzione - Non commerciale - Non opere derivate 4.0 Internazionale. 


\title{
Corinne Saminadayar-Perrin, Les Discours du journal, Rhétorique et médias au XIX siècle (1836-1885)
}

\author{
Philippe Andrès
}

\section{RÉFÉRENCE}

CORINNE SAMINADAYAR-PERRIN, Les Discours du journal, Rhétorique et médias au XIXe siècle (1836-1885), P.U. de Saint-Étienne, 2007, pp. 269.

1 Cet ouvrage, clair de présentation et érudit par son contenu, offre une synthèse honnête de l'histoire du journalisme à la française, de la Monarchie de Juillet à la Troisième République. Les années 1880 voient le triomphe de la grande presse d'information. Dès l'introduction (pp. 8-12), la polyphonie de la presse est soulignée, ainsi que la dette de cette dernière à l'égard de la rhétorique classique.

Dans la première partie, «Scénographies du discours» (pp. 15-94), il est question, dans un premier chapitre («Le journal et la tribune: relais, complémentarité, médiation», pp. 15-41), du rôle du journal dans son lien avec les débats parlementaires. La presse joue un rôle de «porte-voix» (p. 16): une relation étroite se noue entre le journaliste et l'orateur, dans un rapport à la fois conflictuel et complémentaire où l'éloquence règne en reine incontestée. Le deuxième chapitre («L'éloquence en spectacle», pp. 43-68) s'intéresse particulièrement au rôle de plus en plus important de l'avocat «qui se double souvent d'un orateur parlementaire» (p. 44) et devient une véritable «star». Le chapitre III («Mises en perspectives journalistiques des pratiques oratoires», pp. 69-94) clôt cette première partie en soulignant le pouvoir critique du journaliste «comme particulièrement apte à juger des discours en tout genre» (p.70). La presse se transforme ainsi en véritable «laboratoire critique» (p. 77) dont la rhétorique s'inscrit dans un contexte sociopolitique de pratiques d'éloquence bien précis. L'éloquence 
moderne se métamorphose selon les conditions de production du discours dans une rupture avec la tradition rhétorique classique.

La deuxième partie est consacrée aux «Portraits du journaliste en orateur» (pp.97-175). Le chapitre IV s'intéresse tout naturellement au «journaliste» comme «professionnel de l'éloquence» (pp.97-121). Il s'agit d'un journalisme de «forts en thème» (p. 98) qui évolue vers une esthétique de la causerie surtout sous le Second Empire. Le journalisme universitaire occupe une place de plus en plus prépondérante jusqu'en 1870, soulignant ainsi un lien très fort entre la formation rhétorique et l'esprit de la modernité contemporaine. Ainsi s'oriente-t-on vers une véritable «éloquence de la presse» (chapitre V, pp. 123-147) et le journaliste se métamorphose en «avatar de l'orateur» (p. 124) dont l'ironie est l'arme la plus affûtée. Au chapitre VI «Déclarations foraines» (pp.150-175), il est essentiellement question de la «fascination de la petite presse pour le monde des saltimbanques» (p.156) qui incarnent l'authenticité d'une présence populaire. Il est dommage que nulle part il ne soit fait mention de l'œuvre narrative et poétique d'un Banville qui aurait pu illustrer à merveille la thèse défendue dans ce chapitre, notamment lors de l'analyse du lien entre "parodie et subversion» (p. 165)! Le journal devient alors «croisement de paroles», «incessante interaction des discours et des idées» (p. 174).

La troisième et dernière partie s'interroge sur «l'invention d'une éloquence démocratique» (pp. 179- 250). Le chapitre VII constate une «circulation et dégradation des discours» (pp.179-200), car le journal, «premier producteur de cliché», «construit paradoxalement une réflexion sur les clichés» (p. 200). Il revient au chapitre VIII de définir le «nouvel espace de parole» qui apparaît ainsi (pp. 201-226) et aboutit à une véritable «reconfiguration de l'espace public par le journal» (p. 201). On constate une sorte de glissement entre les discours politiques de la Chambre et le rôle de plus en plus important du journal. L'opinion publique s'inscrit ainsi dans le champ idéologique et le journaliste va devenir «la plus prestigieuse incarnation de la figure moderne de l'intellectuel» (p. 222), comme cela sera prouvé au chapitre IX, «L'invention d'un forum moderne» (pp. 227-250). La modernité journalistique se vit, à la fin du xix siècle, comme une métamorphose de la rhétorique ancienne dans une nouvelle esthétique exigeant une clarté d'information passant par des innovations typographiques.

La conclusion (pp. 251-257) reprend clairement l'argumentation de l'ouvrage et souligne la nécessité pour l'homme de lettres héritier de l'idéologie des Lumières de faire face, en fin de siècle, aux impératifs de la presse d'opinion. Cet ouvrage, d'une grande qualité de réflexion et de clarté, ne peut qu'être utile au lecteur soucieux de comprendre les tenants et aboutissants des incessantes métamorphoses des discours de la modernité journalistique. 